\title{
O Uso da Terra no Entorno de Fragmentos Florestais Influencia a sua Composição e Estrutura
}

\author{
Suélen Schramm Schaadt ${ }^{1}$, Alexander Christian Vibrans ${ }^{1}$ \\ ${ }^{1}$ Departamento de Engenharia Florestal, Universidade Regional de Blumenau - FURB, Blumenau/SC, Brasil
}

\section{RESUMO}

Este trabalho teve por objetivo analisar o uso da terra no entorno de 143 unidades amostrais (UA) na floresta ombrófila mista em Santa Catarina e verificar a possível relação do uso da terra com o estado da vegetação. Foram utilizados um mapeamento do uso da terra de 2005 e dados da vegetação coletados em 143 UA do Inventário Florístico Florestal de Santa Catarina (IFFSC) entre 2007 e 2009. O entorno foi delimitado por buffers de distâncias distintas a partir do centro da UA. A cobertura florestal dos entornos e a distância entre a UA e a borda do fragmento apresentaram correlação significativa com riqueza e abundância de espécies climácicas, além de correlação negativa com riqueza e abundância de espécies pioneiras $(\alpha=0,05)$ no fragmento. As paisagens com maior cobertura florestal e com maiores fragmentos permitem a manutenção de florestas mais bem conservadas e com menor influência da matriz no entorno.

Palavras-chave: métricas da paisagem, efeito de borda, floresta ombrófila mista.

\section{Use of Surrounding Land Influences Forest Remants Composition and Structure}

\begin{abstract}
This study aimed to analyze the use of surrounding land of 143 sample plots in the mixed ombrophilous forest in Santa Catarina and investigate a possible relationship of land use with the vegetation status. We used a land use map in 2005 and vegetation data from 143 sample plots (SP) from the Floristic Forest Inventory of Santa Catarina (IFFSC) collected between 2007 and 2009. The surroundings were delimited by buffers of different distances from the SP center. Forest coverage and distance between SP and fragment edge showed significant correlations with richness and abundance of climax species and a negative correlation with richness and abundance of pioneer species $(\alpha=0.05)$ in the fragment. The landscapes with greater forest coverage and larger patches allow the best preserved forest maintenance and show less influence of the surrounding matrix.
\end{abstract}

Keywords: lanscape metrics, edge effect, mixed ombrophilous forest. 


\section{INTRODUÇÃO}

A floresta ombrófila mista cobria originalmente 45\% do território de Santa Catarina, estendendo-se do planalto até o Oeste do Estado (Klein, 1978). A extensa área territorial e o seu valor econômico contribuíram significativamente para a colonização e o desenvolvimento do Estado, assim como para a economia florestal e madeireira do país (Hueck, 1972; Medeiros, 2006).

Entre os anos de 1920 a 1990, a intensa exploração da Araucaria angustifolia (Bertol.) Kuntze, da Ocotea porosa (Nees) Barroso e de outras espécies arbóreas para a produção de madeira reduziu drasticamente a área de abrangência dessa floresta (Thomé, 1995). O desmatamento e as queimadas para a implantação de pastagem, agricultura e reflorestamento homogêneo com espécies exóticas, além da ampliação das zonas urbanas, também contribuíram para a redução da área de ocorrência da floresta ombrófila mista (Medeiros et al., 2005).

Dados do Inventário Florístico Florestal de Santa Catarina (IFFSC), publicados por Vibrans et al. (2011), mostram que 50\% dos remanescentes amostrados da floresta ombrófila mista estão em estágio médio de regeneração e bastante degradados, que $45 \%$ dos fragmentos da vegetação estão em estágio avançado de sucessão e que apenas $5 \%$ dos remanescentes constituem florestas maduras ou primárias.

Parte significativa dessas florestas encontra-se fragmentadas, distribuídas em remanescentes isolados e bastante degradados devido à intensa exploração (Vibrans et al., 2011). A fragmentação florestal é um processo em que as florestas contínuas são divididas em fragmentos de menores extensões e isoladas em meio a uma matriz diferente do habitat original (Cerqueira et al., 2003; Fahrig, 2003).

O isolamento provocado pela fragmentação expõe os remanescentes a diferentes condições climáticas, como redução da umidade do ar e aumento da luminosidade e da temperatura, além de uma maior exposição aos ventos, resultando no declínio do número de espécies existentes no remanescente (Delamônica et al., 2001; Pires et al., 2006). A redução e o isolamento de populações de espécies dificultam o fluxo gênico, podendo causar perda da biodiversidade e até a extinção de espécies (Britez et al., 2003). Por isso a fragmentação florestal é considerada um dos fatores de maior impacto sobre a conservação da biodiversidade (Laurance \& Bierregaard, 1997).

A matriz no entorno dos fragmentos florestais, ou seja, a classe de cobertura da terra de maior área na paisagem, determina o funcionamento desta de acordo com sua relação com os remanescentes (Forman \& Godron, 1986). As alterações bióticas e abióticas que ocorrem principalmente no limite dos fragmentos, denominadas efeitos de borda, influenciam na estrutura da vegetação e nas comunidades de animais (Murcia, 1995; Primack \& Rodrigues, 2001; Olifiers \& Cerqueira, 2006).

Assim, este trabalho teve por objetivo analisar o uso da terra no entorno das unidades amostrais (UA) levantadas pelo Inventário Florístico Florestal na floresta ombrófila mista em Santa Catarina entre 2007 e 2009 e avaliar a influência de fatores como a matriz do entorno e a distância da borda do remanescente sobre a vegetação. Foi estabelecida a hipótese de que os fatores citados determinem diversas características da vegetação de remanescentes florestais, como composição de espécies, estrutura e estado de conservação.

\section{MATERIAL E MÉTODOS}

\section{1. Área de estudo}

A área de estudo compreende o entorno de 143 remanescentes amostrados na floresta ombrófila mista pelo IFFSC entre os anos 2007 e 2009. Os remanescentes florestais foram inventariados a partir da implantação de UA distribuídas de forma sistemática em uma grade de pontos, com distância de $10 \mathrm{~km} \times 10 \mathrm{~km}$ (Vibrans et al., 2010). Os remanescentes analisados situam-se nas regiões Norte, Oeste e Serrana do Estado, entre 500 e $1.600 \mathrm{~m}$ de altitude (Figura 1).

\subsection{Dados utilizados}

As variáveis dendrométricas (diâmetro médio à altura do peito, alturas total e do fuste médias, volume do fuste) e fitossociológicas (número de indivíduos e de espécies no estrato arbóreo e na regeneração, índice de diversidade de Shannon, área basal, densidade e dominância absolutas por espécie, número de espécies e indivíduos pioneiros, secundários e climácicos do estrato arbóreo e da regeneração) da vegetação foram 


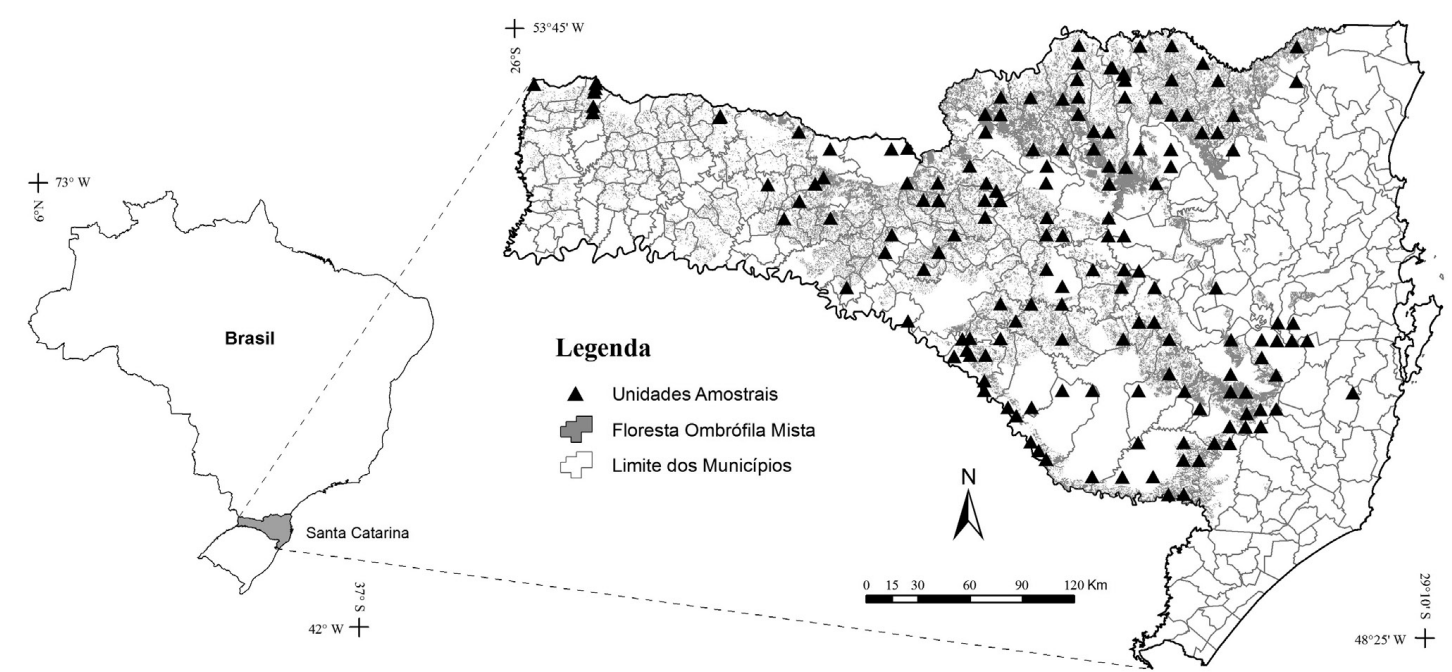

Figura 1. Localização das 143 unidades amostrais (UA) na floresta ombrófila mista em Santa Catarina. Figure 1. Location of 143 sample plots in the Mixed Ombrophilous Forest in Santa Catarina.

obtidas dos dados de campo levantados nas 143 UA do IFFSC na floresta ombrófila mista. O método de amostragem utilizado foi de área fixa em conglomerados de $4.000 \mathrm{~m}^{2}$, compostos por quatro subunidades de $1.000 \mathrm{~m}^{2}$ cada, localizadas a $30 \mathrm{~m}$ de distância do ponto central em direção dos quatro pontos cardeais (Figura 2).

Os dados de uso da terra foram extraídos do Mapeamento Temático Geral do Estado de Santa Catarina, na escala 1:50.000, elaborado para o Projeto de Proteção da Mata Atlântica em Santa Catarina (PPMA/SC), com base em 53 imagens multiespectrais SPOT-4 do ano 2005 (Geoambiente, 2008).

\subsection{Procedimentos de análise}

A análise do entorno das 143 UA consistiu na caracterização do uso da terra, com foco na área de cobertura florestal, e de sua relação com as características da vegetação. Para as análises espaciais foi utilizado o software ArcGIS 9.3.

Essa avaliação foi realizada a partir da criação de faixas circulares, denominadas buffers, com 200, 500, $1.000,2.000,5.000,10.000$ e $20.000 \mathrm{~m}$ de raio a partir do ponto central de cada UA, resultando em áreas de aproximadamente 13, 79, 314, 1.257, 7.854, $31.416 \mathrm{e}$ 125.664 ha, respectivamente. O objetivo de utilizar diferentes áreas de entorno foi verificar a dinâmica da cobertura florestal com o aumento da área analisada.

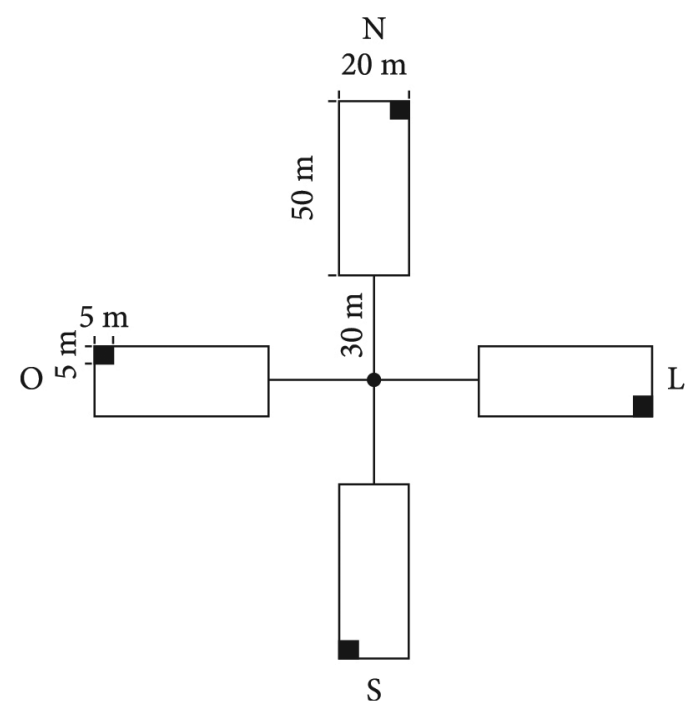

Figura 2. Estrutura do conglomerado para o levantamento de campo do Inventário Florístico Florestal de Santa Catarina (IFFSC).

Figure 2. Structure of the IFFSC field survey cluster.

Os dados da vegetação e do uso da terra foram tabelados em planilha Excel; foram aplicados também a análise de variância (ANOVA) e o teste de comparação de médias Tukey para identificar diferenças significativas na cobertura florestal, nas áreas de lavoura, pastagem, reflorestamento homogêneo e corpos d'água, e nas áreas edificadas entre os buffers (Triola, 1999).

O coeficiente de correlação linear de Pearson foi calculado com o objetivo de verificar a relação entre 
a percentagem de cobertura florestal de cada buffer e as variáveis da vegetação levantadas nas UA.

Esse coeficiente também foi utilizado para verificar se as variáveis da vegetação nas UA podem ser influenciadas pela distância dessas unidades à borda do remanescente.

\section{RESULTADOS E DISCUSSÃO}

\subsection{Uso da terra nos fragmentos e no seu entorno}

Utilizando-se o buffer com $200 \mathrm{~m}$ de raio, aproximadamente $83 \%$ da área corresponde à classe floresta em estágio médio ou avançado de regeneração e/ou floresta primária, seguido por lavoura e pastagem (14\%), reflorestamento (3\%) e floresta em estágio inicial (1\%) (Figura 3).

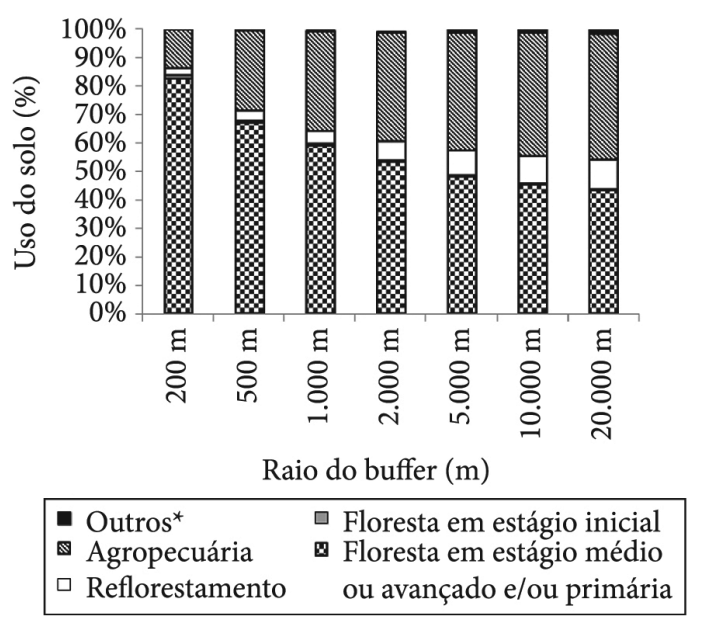

Figura 3. Uso da terra no entorno das unidades amostrais (UA). * Corpos d'água e área edificada.

Figure 3. Land use in the surroundings of sample plots. * Waterbodies and Built-up areas.
$\mathrm{Na}$ área de maior abrangência (buffer com 20.000 m de raio), as classes lavoura e pastagem ocuparam $45 \%$ da área total, superior à classe floresta em estágio médio ou avançado, com 43\%, e à classe reflorestamento, que ocupou $10 \%$ dessa área. As demais classes somaram apenas $2 \%$ da área analisada.

Pode-se observar que, quanto maior a área analisada, menor a cobertura florestal relativa em estágio avançado e maior o uso da terra para lavoura, pastagem e reflorestamento, sendo essas as classes de maior representatividade nas seis áreas analisadas.

A ANOVA e o teste de Tukey $(\alpha=0,05)$ indicam que ocorreu diferença significativa entre os valores de cobertura florestal e das demais classes de uso da terra nos buffers (Tabela 1), exceto para floresta em estágio inicial.

Os valores nas classes floresta em estágio médio ou avançado e/ou floresta primária e lavoura e pastagem apresentaram diferença significativa entre os buffers 200, 500 e 1.000 m. Porém, a partir do buffer 5.000 m, os valores nas classes de uso da terra entre os buffers não foram significativamente diferentes.

O predomínio das classes floresta em estágio médio ou avançado de regeneração e/ou floresta primária, lavoura, pastagem e reflorestamento é reflexo do processo de ocupação e de desenvolvimento da região de abrangência da floresta ombrófila mista em Santa Catarina. A economia era baseada principalmente na exploração madeireira e na agropecuária (Goularti, 2007). Com o esgotamento dos recursos naturais, a partir da década de 1970, iniciaram-se os reflorestamentos, principalmente com Pinus sp., para garantir a produção madeireira (Hoff \& Simioni, 2004).

As três classes de uso da terra de maior representatividade no presente estudo corroboram

Tabela 1. Valores médios (\%) das classes de uso da terra e diferenças significativas entre as áreas dos buffers $(\alpha=0,05)$. Letras diferentes indicam diferença significativa.

Table 1. Mean values (\%) of land use classes and significant differences between buffers areas $(\alpha=0,05)$. Different letters indicate significant difference.

\begin{tabular}{lccccccc} 
& \multicolumn{7}{c}{ Buffer $(\mathbf{m})$} \\
\cline { 2 - 8 } \multicolumn{1}{c}{ Classes de uso da terra } & $\mathbf{2 0 0} \mathbf{~ m}$ & $\mathbf{5 0 0} \mathbf{~ m}$ & $\mathbf{1 . 0 0 0} \mathbf{~ m}$ & $\mathbf{2 . 0 0 0} \mathbf{~ m}$ & $\mathbf{5 . 0 0 0} \mathbf{~ m}$ & $\mathbf{1 0 . 0 0 0} \mathbf{~ m}$ & $\mathbf{2 0 . 0 0 0} \mathbf{~ m}$ \\
\hline $\begin{array}{l}\text { Floresta em estágio médio ou } \\
\text { avançado e/ou primária }\end{array}$ & $82,56 \mathrm{a}$ & $67,10 \mathrm{~b}$ & $59,00 \mathrm{c}$ & $53,48 \mathrm{~cd}$ & $48,09 \mathrm{de}$ & $45,35 \mathrm{e}$ & $42,94 \mathrm{e}$ \\
Reflorestamento & $2,50 \mathrm{a}$ & $3,67 \mathrm{ab}$ & $4,53 \mathrm{ab}$ & $6,72 \mathrm{bc}$ & $8,9 \mathrm{~cd}$ & $9,67 \mathrm{~cd}$ & $10,16 \mathrm{~d}$ \\
\hline Agropecuária & $13,55 \mathrm{a}$ & $27,91 \mathrm{~b}$ & $35,04 \mathrm{c}$ & $38,33 \mathrm{~cd}$ & $41,48 \mathrm{cde}$ & $43,37 \mathrm{de}$ & $45,19 \mathrm{e}$ \\
Outros $^{*}$ & - & $0,37 \mathrm{a}$ & $0,70 \mathrm{ab}$ & $0,98 \mathrm{ab}$ & $1,09 \mathrm{ab}$ & $1,09 \mathrm{ab}$ & $1,25 \mathrm{~b}$ \\
\hline
\end{tabular}

${ }^{*}$ Corpos d'água e área edificada. 
com estudos realizados em regiões específicas de abrangência da floresta ombrófila mista em Santa Catarina. Kurasz et al. (2008) analisou uma faixa de $2 \mathrm{~km}$ no entorno da Reserva Florestal EMBRAPA/EPAGRI, com 1.157,48 ha, em Caçador-SC, onde o uso da terra é caracterizado por reflorestamento (37,54\%), lavoura e pastagem $(28,06 \%)$ e vegetação nativa $(21,47 \%)$.

Mapeando a vegetação e o uso da terra na área do Parque Nacional de São Joaquim, Alarcon \& Silva (2007) constataram que as pastagens constituem a categoria de uso da terra mais representativa dentro dos limites do Parque, considerando de extrema necessidade a recuperação da vegetação original nessa área.

Na sub-bacia delimitada como área do Corredor Ecológico Chapecó, Alarcon et al. (2011) estudaram a fragmentação florestal e constataram que, dos $5.000 \mathrm{~km}^{2}$ do corredor, 50,5\% são remanescentes florestais e 42,7\% são lavouras e pastagens. Diante do intenso processo de fragmentação ao qual a floresta ombrófila mista foi submetida, os autores consideram a conservação desses últimos remanescentes florestais contínuos presentes no Corredor Ecológico Chapecó de extrema importância para a região Oeste Catarinense.

Grande parte dos remanescentes da floresta ombrófila mista está em uma matriz agrícola e/ou pecuária, inclusive unidades de conservação, como pode ser constatado nos estudos citados. Os efeitos da fragmentação florestal são reduzidos quando a estrutura da matriz é semelhante à da floresta adjacente, o que não ocorre em áreas agropecuárias (Gascon et al., 1999). Já áreas de reflorestamento podem representar um benefício para a conservação de fragmentos florestais, pois atenuam o efeito de borda e diminuem o risco de incêndio (Viana \& Pinheiro, 1998). Silveira et al. (2008) relatam que a matriz na qual o fragmento está inserido representa o segundo fator de maior importância e influência para os riscos de incêndios florestais.

O coeficiente de correlação entre a percentagem de cobertura florestal em cada buffer e as características dendrométricas e fitossociológicas da vegetação nas UA indica a influência da heterogeneidade da matriz sobre a vegetação dos remanescentes, a partir de seis áreas crescentes de abrangência (Tabela 2).

Tabela 2. Correlação entre a cobertura florestal em cada buffer e as variáveis da vegetação.

Table 2. Correlation between the forest cover in each buffer and vegetation parameters.

\begin{tabular}{|c|c|c|c|c|c|c|c|}
\hline \multirow{2}{*}{ Variáveis da vegetação } & \multicolumn{7}{|c|}{ Buffer $(\mathbf{m})$} \\
\hline & 200 & 500 & 1.000 & 2.000 & 5.000 & 10.000 & 20.000 \\
\hline Número de indivíduos no estrato arbóreo & $0,20^{+}$ & $0,22^{+}$ & $0,18^{*}$ & $0,21^{+}$ & $0,29^{\#}$ & $0,33^{\#}$ & $0,29^{\#}$ \\
\hline Número de espécies no estrato arbóreo & $0,14^{*}$ & $0,02^{*}$ & $0,07^{*}$ & $0,11^{*}$ & $0,07^{*}$ & $0,09^{*}$ & $0,10^{*}$ \\
\hline Índice de Shannon (nat./ind.) & $0,00^{*}$ & $-0,16^{*}$ & $-0,15^{\star}$ & $-0,17^{\star}$ & $-0,24^{+}$ & $-0,21^{+}$ & $-0,13^{\star}$ \\
\hline Área basal $\left(\mathrm{m}^{2} / \mathrm{ha}\right)$ & $0,31^{\#}$ & $0,37^{\#}$ & $0,29^{\#}$ & $0,29^{\#}$ & $0,31^{\#}$ & $0,29^{\#}$ & $0,21^{+}$ \\
\hline Densidade absoluta ( $\mathrm{n}^{\circ}$ ind./ha) & $0,16^{*}$ & $0,20^{+}$ & $0,17^{\star}$ & $0,21^{+}$ & $0,31^{\#}$ & $0,35^{\#}$ & $0,31^{\#}$ \\
\hline Dominância absoluta $\left(\mathrm{m}^{2} / \mathrm{ha}\right)$ & $0,28^{\#}$ & $0,36^{\#}$ & $0,29^{*}$ & $0,28^{\#}$ & $0,32^{\#}$ & $0,29^{\#}$ & $0,22^{+}$ \\
\hline Diâmetro médio à altura do peito $(\mathrm{m})$ & $0,18^{*}$ & $0,23^{+}$ & $0,19^{*}$ & $0,10^{*}$ & $0,04^{*}$ & $-0,03^{*}$ & $-0,07^{\star}$ \\
\hline Altura total média (m) & $0,03^{*}$ & $-0,14^{*}$ & $-0,17^{*}$ & $-0,27^{\#}$ & $-0,33^{\#}$ & $-0,33^{\#}$ & $-0,25^{+}$ \\
\hline Altura do fuste média (m) & $0,00^{*}$ & $-0,13^{*}$ & $-0,18^{*}$ & $-0,24^{+}$ & $-0,28^{\#}$ & $-0,31^{\#}$ & $-0,28^{\#}$ \\
\hline Número de indivíduos na regeneração & $-0,13^{*}$ & $-0,13^{*}$ & $-0,09^{*}$ & $-0,05^{\star}$ & $0,04^{*}$ & $0,05^{*}$ & $0,07^{\star}$ \\
\hline Número de espécies na regeneração & $-0,04^{*}$ & $-0,11^{*}$ & $-0,09^{*}$ & $-0,04^{*}$ & $-0,01^{*}$ & $0,04^{*}$ & $0,06^{*}$ \\
\hline Volume do fuste $\left(\mathrm{m}^{3}\right)$ & $0,14^{*}$ & $-0,01^{*}$ & $-0,12^{*}$ & $-0,17^{\star}$ & $-0,22^{+}$ & $-0,25^{+}$ & $-0,25^{+}$ \\
\hline Espécies pioneiras no estrato arbóreo (\%) & $-0,14^{*}$ & $-0,27^{\#}$ & $-0,21^{+}$ & $-0,20^{+}$ & $-0,21^{+}$ & $-0,25^{+}$ & $-0,20^{+}$ \\
\hline Espécies secundárias no estrato arbóreo (\%) & $0,12^{*}$ & $-0,04^{*}$ & $0,00^{*}$ & $0,02^{*}$ & $-0,02^{*}$ & $0,02^{*}$ & $0,07^{\star}$ \\
\hline Espécies climácicas no estrato arbóreo (\%) & $0,32^{\#}$ & $0,44^{\#}$ & $0,45^{\#}$ & $0,47^{\#}$ & $0,45^{\#}$ & $0,44^{\#}$ & $0,39^{\#}$ \\
\hline Indivíduos pioneiros no estrato arbóreo (\%) & $-0,11^{*}$ & $-0,28^{\#}$ & $-0,31^{\#}$ & $-0,27^{\#}$ & $-0,21^{+}$ & $-0,23^{+}$ & $-0,23^{+}$ \\
\hline Indivíduos secundários no estrato arbóreo (\%) & $0,05^{*}$ & $-0,21^{+}$ & $-0,27^{\#}$ & $-0,25^{+}$ & $-0,24^{+}$ & $-0,20^{+}$ & $0,15^{*}$ \\
\hline Indivíduos climácicos no estrato arbóreo (\%) & $0,25^{+}$ & $0,43^{\#}$ & $0,40^{\#}$ & $0,37^{\#}$ & $0,39^{\#}$ & $0,40^{\#}$ & $0,30^{\#}$ \\
\hline Espécies pioneiras na regeneração (\%) & $-0,11^{\star}$ & $-0,21^{+}$ & $-0,22^{+}$ & $-0,20^{+}$ & $-0,22^{+}$ & $-0,20^{+}$ & $-0,25^{+}$ \\
\hline Espécies secundárias na regeneração (\%) & $-0,08^{*}$ & $-0,24^{+}$ & $-0,22^{+}$ & $-0,15^{\star}$ & $-0,15^{*}$ & $-0,10^{*}$ & $-0,07^{\star}$ \\
\hline Espécies climácicas na regeneração (\%) & $0,05^{\star}$ & $0,01^{*}$ & $-0,01^{*}$ & $0,04^{*}$ & $0,07^{\star}$ & $0,15^{\star}$ & $0,20^{+}$ \\
\hline Indivíduos pioneiros na regeneração (\%) & $-0,09^{*}$ & $-0,11^{*}$ & $-0,11^{*}$ & $-0,22^{+}$ & $-0,26^{\#}$ & $-0,33^{\#}$ & $-0,33^{\#}$ \\
\hline Indivíduos secundários na regeneração (\%) & $-0,12^{*}$ & $-0,29^{\#}$ & $-0,28^{\#}$ & $-0,18^{*}$ & $-0,20^{+}$ & $-0,17^{\star}$ & $-0,18^{*}$ \\
\hline Indivíduos climácicos na regeneração (\%) & $0,04^{*}$ & $-0,10^{*}$ & $-0,16^{*}$ & $-0,13^{*}$ & $-0,12^{*}$ & $-0,09^{*}$ & $-0,04^{*}$ \\
\hline
\end{tabular}

*correlação não significativa. + correlação positiva ou negativa significativa para $\alpha=0,05$. \#correlação positiva ou negativa significativa para $\alpha=0,01$. 
A percentagem de cobertura florestal está positivamente correlacionada com o número de indivíduos do estrato arbóreo, porém não apresenta correlação significativa com o número de indivíduos da regeneração. Ao analisar a percentagem desses indivíduos por grupo ecológico, tem-se uma correlação positiva entre a percentagem de indivíduos climácicos do estrato arbóreo e a área de cobertura florestal. Por sua vez, a percentagem de indivíduos pioneiros, tanto do estrato arbóreo quanto da regeneração, apresenta uma correlação negativa com a área de cobertura florestal, assim como a percentagem de indivíduos secundários do estrato arbóreo e da regeneração.

Resultado similar pode ser observado para as espécies. Apesar de não haver correlação significativa entre o número de espécies (riqueza) do estrato arbóreo e da regeneração e a percentagem de cobertura florestal, ao analisar a percentagem de espécies por grupos ecológicos, tem-se uma correlação positiva entre a percentagem de espécies climácicas do estrato arbóreo e a área de cobertura florestal e uma correlação negativa entre a percentagem de espécies pioneiras, tanto do estrato arbóreo quanto da regeneração, e a área de cobertura florestal. A percentagem de espécies secundárias não apresentou correlação significativa com a área de cobertura florestal.

De acordo com esses resultados, pode-se concluir que áreas com maior cobertura florestal apresentam um predomínio de espécies climácicas, mais exigentes quanto às condições ambientais. Espécies pioneiras estão presentes em maior quantidade em áreas mais perturbadas e com menor cobertura florestal, com fragmentos isolados por uma matriz geralmente agrícola ou pecuária. As espécies secundárias apresentam uma tendência similar às espécies pioneiras.

Padrão similar foi verificado por Bernacci et al. (2006), ao avaliarem os efeitos do processo de fragmentação na composição e na riqueza arbórea em duas paisagens, uma florestal e uma agrícola, no Planalto de Ibiúna-SP. A paisagem florestal, com 9.400 ha, apresentou um maior número de espécies arbóreas, sendo estas principalmente secundárias tardias. A paisagem agrícola, composta por 21 fragmentos florestais com tamanho entre 0,9 e 275 ha, apresentou principalmente espécies pioneiras e secundárias iniciais, em decorrência da fragmentação. Os autores ressaltam o empobrecimento da vegetação e a consequente perda de habitat nos fragmentos florestais devido à fragmentação, além de evidenciarem a importância dos fragmentos remanescentes, pois estes apresentam algumas espécies ameaçadas de extinção, pouco conhecidas ou inéditas na região.

A composição e a riqueza da floresta também são alteradas pela fragmentação. Espécies pioneiras, adaptadas a perturbações, são favorecidas por esse processo, em detrimento das espécies climácicas, de florestas maduras (Delamônica et al., 2001). No presente estudo, entretanto, o índice de Shannon não apresentou correlação significativa com a percentagem de cobertura florestal.

A percentagem de cobertura florestal apresentou correlação positiva com a densidade absoluta e com a dominância absoluta e negativa com altura total média, altura do fuste média e volume do fuste. Dessa forma, áreas com maior cobertura florestal e mais bem conservadas apresentam maior densidade e dominância (também representada pela área basal) absolutas de indivíduos, enquanto áreas com maior fragmentação da floresta apresentam maior altura e volume dos indivíduos.

\subsection{Distância das UA à borda do remanescente}

A análise da distância entre a UA e a borda do remanescente procurou verificar se essa distância influencia as características dendrométricas e fitossociológicas da vegetação presente nas UA. Segundo Godefroid \& Koedam (2003), a composição de espécies e a estrutura de comunidade da vegetação na borda da floresta são tipicamente diferentes da vegetação no interior desta, visto que as influências do efeito de borda ocorrem com maior intensidade nas proximidades da borda do remanescente e tendem a se amenizar em direção ao interior (Delamônica et al., 2001; Pires et al., 2006).

Murcia (1995) classifica o efeito de borda em fragmentos em três tipos: efeitos abióticos, os quais envolvem mudanças nas condições ambientais devido à proximidade entre o fragmento e a área alterada; efeitos biológicos diretos, caracterizados pelas alterações na abundância e na distribuição das espécies devido às condições físicas próximas à borda; efeitos biológicos indiretos, os quais envolvem mudanças nas interações ecológicas. 
Das 143 UA levantadas, apenas 15\% estão a menos de $49 \mathrm{~m}$ da borda; aproximadamente $26 \%$ estão entre 50 e $99 \mathrm{~m}$ da borda; 31\%, a uma distância entre 100 e 199 m; 19\%, entre 200 e 499 m; ainda 8\% das UA estão a mais de $500 \mathrm{~m}$ de distância da borda.

A distância entre a UA e a borda do fragmento apresentou correlações significativas com algumas variáveis da vegetação (Figura 4). A correlação foi positiva com dominância absoluta, DAP, número de espécies e de indivíduos climácicos do estrato arbóreo. No entanto, a correlação foi negativa com número de espécies e de indivíduos pioneiros do estrato arbóreo e de indivíduos secundários do estrato arbóreo e da regeneração.

Dessa forma, pode-se observar que a vegetação mais próxima à borda do fragmento tende a ser formada por espécies pioneiras e secundárias. Já no interior dos fragmentos, prevalecem as espécies climácicas, com maior dominância na floresta e maior diâmetro do fuste.

Esse fato corrobora com a teoria dos grupos sucessionais das espécies na ecologia. De acordo com Scariot et al. (2003), em remanescentes isolados pela fragmentação florestal há um intenso efeito de borda que favorece o crescimento de espécies pioneiras, pois estas se desenvolvem em grandes clareiras, bordas de fragmentos florestais, locais abertos e áreas degradadas (Almeida, 2000), enquanto que as espécies climácicas

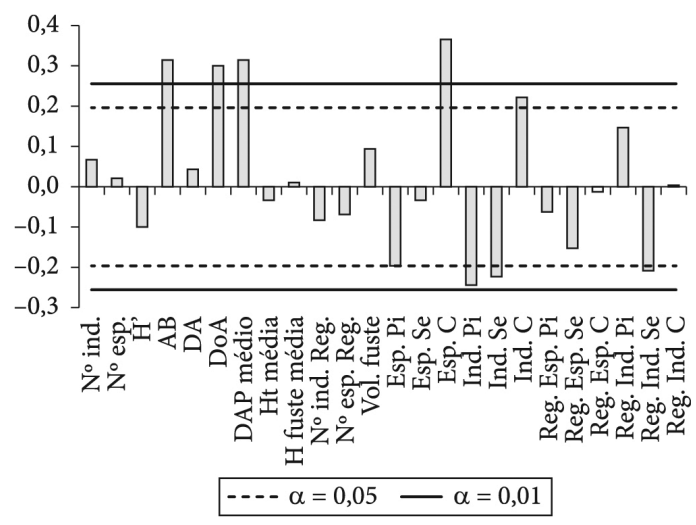

Figura 4. Correlação entre a distância da unidade amostral (UA) da borda do remanescente e as variáveis da vegetação; linhas horizontais indicam valores significativos.

Figure 4. Correlation between distance from sample plots to edge of forest remnant and vegetation parameters; horizontal lines indicate significative values. se adaptam em ambientes mais conservados e com maior sombreamento.

Resultado semelhante foi encontrado na Amazônia central brasileira por Nascimento \& Laurance (2006). Apesar de não ter encontrado relação entre espécies tardias e distância da borda, os autores mostraram que a densidade de espécies pioneiras é maior em locais mais próximos à borda, onde há maior mortalidade de árvores.

Uma redução de plantas pioneiras a partir dos $30 \mathrm{~m}$ de borda foi verificada por Rigueira et al. (2012) em um fragmento de floresta tropical submontana na Bahia. De acordo com os autores, esse fato pode ser explicado pelo aumento do adensamento foliar e pela diminuição da disponibilidade de luz.

Diferenças significativas na proporção de espécies arbóreas pioneiras e emergentes na borda e no interior do fragmento foram encontradas por Oliveira et al. (2004), sendo que a borda apresentou duas vezes mais espécies pioneiras comparada ao interior e apenas um terço das espécies emergentes presentes no interior. No geral, 24\% foram exclusivas da borda da floresta, $57 \%$ foram exclusivas do interior da floresta e 19\% foram comuns nos dois habitats.

Em estudo sobre perturbação na floresta tropical perene em Eastern Ghats, na Índia, Chittibabu \& Parthasarathy (2000) encontraram redução na riqueza, diversidade e composição de espécies, assim como na densidade de espécies e na área basal, com o aumento da perturbação em relação a áreas não perturbadas. Cadotte et al. (2002) estudaram um fragmento florestal em uma área bastante degradada e três fragmentos florestais próximos a uma floresta conservada, todas no sudeste de Madagascar, e também observaram uma redução na densidade de árvores e na riqueza e diversidade de espécies na região mais degradada. Não observaram, porém, diferença significativa no diâmetro e na altura das árvores.

No presente estudo, riqueza, diversidade e densidade de espécies não apresentaram correlação significativa com a distância da UA à borda, diferindo dos resultados encontrados por Chittibabu \& Parthasarathy (2000) e Cadotte et al. (2002); já a área basal apresentou-se maior em UA mais distantes da borda, corroborando com o estudo de Chittibabu \& Parthasarathy (2000). O diâmetro médio também foi maior em UA mais distantes da borda no presente estudo, o que não 
foi encontrado por Cadotte et al. (2002), que não observaram diferença significativa entre as áreas degradada e conservada.

\section{CONCLUSÕES}

A matriz circundante dos remanescentes da floresta ombrófila mista de Santa Catarina é composta principalmente por campos, lavouras e reflorestamentos.

Quanto maior a área do fragmento florestal, maior é o estabelecimento e a permanência de espécies climácicas, enquanto que as espécies pioneiras e secundárias provavelmente sejam favorecidas por florestas mais perturbadas (fragmentadas). A densidade e a dominância de diversas espécies são maiores em áreas com maior cobertura florestal, entretanto a diversidade não parece ser influenciada.

Quanto maior a distância da borda, maior é a ocorrência de espécies climácicas e árvores com maior DAP médio e área basal. Nas bordas, no entanto, ocorre um maior número de espécies pioneiras e secundárias.

Paisagens com maior cobertura florestal permitem a existência ou a sobrevivência de florestas mais bem conservadas e com menor influência da matriz no entorno. Esse resultado também está em conformidade com a teoria da ecologia da paisagem e mostra a importância dos conceitos desta para ações de conservação.

\section{STATUS DA SUBMISSÃO}

Recebido: 15 out., 2013

Aceito: 8 jun., 2015

\section{AUTOR(ES) PARA CORRESPONDÊNCIA}

\section{Suélen Schramm Schaadt}

Departamento de Engenharia Florestal, Universidade Regional de Blumenau - FURB, Rua Antônio da Veiga, 140, Victor Konder, CEP 89012-900, Blumenau, SC, Brasil e-mail: suelen_sch@yahoo.com.br

\section{REFERÊNCIAS}

Alarcon GG, Da-Ré MA, Fukahori STI, Zanella LR. Fragmentação da Floresta com Araucária e ecossistemas associados no Corredor Ecológico Chapecó, Santa Catarina. Biotemas 2011; 24(3): 25-38.
Alarcon GG, Silva EH. Mapeamento e caracterização da cobertura vegetal e uso do solo do Parque Nacional de São Joaquim - SC. Revista Discente Expressões Geográficas 2007; 3: 121-141.

Almeida DS. Recuperação ambiental da Mata Atlântica. Ilhéus: Editus; 2000.

Bernacci LC, Franco GADC, Àrbocz GF, Catharino ELM, Durigan G, Metzger JP. O efeito da fragmentação florestal na composição e riqueza de árvores na região da Reserva Morro Grande (Planalto de Ibiúna, SP). Revista do Instituto Florestal 2006; 18(1): 121-166.

Britez RM, Alger K, Baumgarten JE, Castella PR, Cullen L Jr, Faria DM et al. Manejo no entorno. In: Rambaldi DM, Oliveira DAS, organizadores. Fragmentação de ecossistemas: causas, efeitos sobre a biodiversidade e recomendações de políticas públicas. Brasília: MMA: SBF; 2003.

Cadotte MW, Franck R, Reza L, Lovett-Doust J. Tree and shrub diversity and abundance in fragmented littoral forest of southeastern Madagascar. Biodiversity and Conservation 2002; 11(8): 1417-1436. http://dx.doi. org/10.1023/A:1016282023542.

Cerqueira R, Brant A, Nascimento MT, Pardini R. Fragmentação: alguns conceitos. In: Rambaldi DM, Oliveira DAS, organizadores. Fragmentação de ecossistemas: causas, efeitos sobre a biodiversidade e recomendações de politicas públicas. Brasília: MMA: SBF; 2003.

Chittibabu CV, Parthasarathy N. Attenuated tree species diversity in human-impacted tropical evergreen forest sites at Kolli hills, Eastern Ghats, India. Biodiversity and Conservation 2000; 9(11): 1493-1519. http://dx.doi. org/10.1023/A:1008971015545.

Delamônica P, Laurance WF, Laurance SG. A fragmentação da paisagem. In: Oliveira AA, Daly DC, editores. Florestas do Rio Negro. São Paulo: Companhia das Letras: UNIP; 2001.

Fahrig L. Effects of habitat fragmentation on biodiversity. Annual Review of Ecology Evolution and Systematics 2003; 34(1): 487-515. http://dx.doi.org/10.1146/annurev. ecolsys.34.011802.132419.

Forman RTT, Godron M. Landscape ecology. New York: John Wiley e Sons; 1986.

Gascon C, Lovejoy TE, Bierregaard RO Jr, Malcolm JR, Stouffer PC, Vasconcelos HL et al. Matrix habitat and species richness in tropical Forest remnants. Biological Conservation 1999; 91(2-3): 223-229. http://dx.doi. org/10.1016/S0006-3207(99)00080-4.

Geoambiente. Mapeamento temático geral do Estado de Santa Catarina. Relatório Técnico do Projeto de Proteção da Mata Atlântica em Santa Catarina (PPMA/SC). GEORLT-C0715-33608-01. 2008.

Godefroid S, Koedam N. Distribution pattern of the flora in a peri-urban forest: an effect of the city-forest ecotone. Landscape and Urban Planning 2003; 65(4): 169-185. http:// dx.doi.org/10.1016/S0169-2046(03)00013-6. 
Goularti A Fo. Formação econômica de Santa Catarina. 2. ed. Florianópolis: UFSC; 2007.

Hoff DN, Simioni FJ. O setor de base florestal na serra catarinense. Lages: Uniplac; 2004.

Hueck K. As florestas da América do Sul: ecologia, composição e importância econômica. São Paulo: Polígono; 1972.

Klein RM. Contribuição ao conhecimento da flora e da vegetação do Vale do Itajaí, Santa Catarina [tese]. São Paulo: Universidade de São Paulo; 1978.

Kurasz G, Rosot NC, Oliveira YMM, Rosot MAD. Caracterização do entorno da Reserva Florestal EMBRAPA/ EPAGRI de Caçador (SC) usando imagem Ikonos. Floresta 2008; 38(4): 641-649. http://dx.doi.org/10.5380/ rf.v38i4.13159.

Laurance WF, Bierregaard RO. Tropical forest remnants. Chicago: University of Chicago Press; 1997.

Medeiros JD, Savi M, Brito BFA. Seleção de áreas para criação de unidades de conservação na Floresta Ombrófila Mista. Biotemas 2005; 18(2): 33-50.

Medeiros JD. Os estados da Mata Atlântica: Santa Catarina. In: Campanili M, Prochnow M, organizadores e editores. Mata Atlântica, uma rede pela floresta. Brasília: RMA; 2006.

Murcia C. Edge effects in fragmented forests: implications for conservation. Trends in Ecology \& Evolution 1995; 10(2): 58-62. http://dx.doi.org/10.1016/S0169-5347(00)88977-6. PMid:21236953.

Nascimento HEM, Laurance WF. Efeitos de área e de borda sobre a estrutura florestal em fragmentos de floresta de terra-firme após 13-17 anos de isolamento. Acta Amazonica 2006; 36(2): 183-192. http://dx.doi. org/10.1590/S0044-59672006000200008.

Olifiers N, Cerqueira R. Fragmentação de habitat: efeitos históricos e ecológicos. In: Rocha CFD, Bergallo HG, van Sluys M, Alice MAS, organizadores. Biologia da Conservação: essências. São Carlos: RiMa; 2006.

Oliveira MA, Grillo AS, Tabarelli M. Forest edge in the Brazilian Atlantic forest: drastic changes in tree species assemblages. Oryx 2004; 38(4): 389-394. http://dx.doi. org/10.1017/S0030605304000754.

Pires AS, Fernandez FAZ, Barros CS. Vivendo em um mundo em pedaços: efeitos da fragmentação florestal sobre comunidades e populações animais. In: Rocha CFD,
Bergallo HG, van Sluys M, Alice MAS, organizadores. Biologia da conservação: essências. São Carlos: RiMa; 2006.

Primack RB, Rodrigues E. Biologia da conservação. Londrina: Planta; 2001.

Rigueira DMG, Molinari ALM, Mariano DLS, Reis RM, Portugal AB, Santana NSS et al. Influência da distância da borda e do adensamento foliar sobre a abundância de plantas pioneiras em um fragmento de floresta tropical submontana na Estação ecológica de Wenceslau Guimarães (Bahia, Brasil). Acta Botanica Brasílica 2012; 26(1): $197-$ 202. http://dx.doi.org/10.1590/S0102-33062012000100019.

Scariot A, Freitas SM, Mariano E No, Nascimento MT, Oliveira LC, Sanaiotti T et al. Vegetação e flora. In: Rambaldi DM, Oliveira DAS, organizadoras. Fragmentação de ecossistemas: causas, efeitos sobre a biodiversidade e recomendações de políticas públicas. Brasília: MMA: SBF; 2003.

Silveira HFL, Vettorazzi CA, Valente ROA. Avaliação multicriterial no mapeamento de risco de incêndios florestais, em ambiente SIG, na Bacia do Rio Corumbataí, SP. Revista Árvore 2008; 32(2): 259-268. http://dx.doi. org/10.1590/S0100-67622008000200009.

Thomé N. Ciclo da Madeira: história da devastação da Floresta da Araucária e do desenvolvimento da indústria da madeira em Caçador e na região do Contestado no século XX. Caçador: Universal; 1995.

Triola MF. Introdução à estatística. 7. ed. Rio de Janeiro: LTC; 1999.

Viana VM, Pinheiro LAFV. Conservação da biodiversidade em fragmentos florestais. Série Técnica IPEF 1998; 12(32): 25-42.

Vibrans AC, Sevegnani L, Uhlmann A, Schorn LA, Sobral MG, de Gasper AL et al. Structure of mixed ombrophyllous forests with Araucaria angustifolia (Araucariaceae) under external stress in Southern Brazil. Revista de Biologia Tropical 2011; 59(3): 1371-1387. PMid:22017139.

Vibrans AC, Sevgnani L, Lingner DV, Gasper AL, Sabbagh S. Inventário florístico florestal de Santa Catarina (IFFSC): aspectos metodológicos e operacionais. Pesquisa Florestal Brasileira 2010; 30(64): 291-302. http://dx.doi. org/10.4336/2010.pfb.30.64.291. 